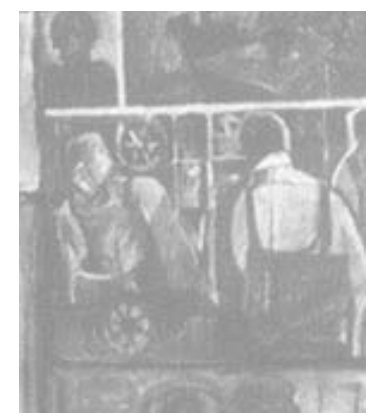

\title{
Idosos em cena: falas do adoecer
}

\author{
Maria Alice Amorim Garcia ${ }^{1}$ \\ Ana Paula de Carvalho Odoni² \\ Caio Silvério de Souza ${ }^{3}$ \\ Rafaela Marega Frigério ${ }^{4}$ \\ Silvia Stahl Merlin ${ }^{5}$
}

GARCIA, M. A. A. et al. Senior citizens in the limelight: the discourses of illness. Interface - Comunic., Saúde, Educ., v.9, n.18, p.537-52, set/dez 2005.

Concerned with improving the quality of the healthcare provided to senior citizens and with the resolvability of their health problems, and knowing that they often suffer from multiple, hard to control morbidities that are difficult to prevent, we tried to develop a better understanding of this problem from the standpoint of the main actors themselves, by listening to their interpretation of the process of falling ill and of the care required. The qualitative study conducted indicates that the perception of falling ill among the aged is based on the context of their lives and also relies on ability to work as a reference. Access to healthcare services and a technical knowledge of the illnesses were demonstrated, as evidenced by the description of signs and symptoms, causes and other associated factors. However, as personal experiences that encompass undergoing care, these discourses ought to be shared and the mediations they involve analyzed, to enable healthcare professionals to come closer to the context of falling ill and aging, as well as to the process of acceptance, thus making it easier for them to provide integral care, based on the quest for autonomy.

KEY WORDS: senior citizen health. perception. illness. aging.

Tendo por preocupação a melhor qualidade e resolutividade na atenção à saúde dos idosos e sabendo serem eles portadores de um quadro de múltipla morbidade de difícil controle e prevenção, buscou-se conhecer este problema sob a perspectiva dos próprios sujeitos: seu entendimento acerca do processo de adoecimento e dos cuidados necessários. Por meio de estudo qualitativo, constatou-se que a percepção do adoecer entre os idosos fundamenta-se em seu contexto de vida e na referência da capacidade para o trabalho. Foram demonstrados o acesso a serviços de saúde e o conhecimento técnico das enfermidades, descritas pela presença de sinais e sintomas, e fatores causais e associados. Entretanto, enquanto experiências pessoais que incorporam vivências de cuidado, as narrativas necessitam ser compartilhadas, analisando-se suas mediações o que permitiria aos profissionais de saúde uma aproximação ao contexto do adoecer e do envelhecer, e ao processo de aceitação e, assim, a um cuidado integral e fundado na busca de autonomia.

PALAVRAS-CHAVE: saúde do idoso. percepção. adoecimento. envelhecimento.

\footnotetext{
${ }^{1}$ Docente, Centro de Ciências da Vida, Faculdade de Medicina, Pontifícia Universidade Católica de Campinas, Puccamp, Campinas. <malicegarcia@puc-campinas.edu.br>

2,3 Bolsistas PIBIC/CNPq; Grupo de pesquisa Intervenções em Saúde: avaliando invenções.

${ }^{4,5}$ Acadêmicos, Faculdade de Medicina, Puccamp, Campinas.
}

${ }^{1}$ Rua Américo de Campos, 416,

Cidade Universitária, Campinas, SP,

CEP:13083-040 
O cenário

O envelhecimento não começa subitamente aos sessenta anos, mas consiste no acúmulo e interação de processos bio-psico-sócio-culturais durante toda a vida que podem constituir fatores de adoecimento ou promotores de saúde $e$ de bem estar.

A população brasileira tem apresentado um crescimento progressivo de idosos, devendo passar, entre 1960 e 2025, da $16^{\text {a }}$ para a sexta posição mundial em relação a este contingente populacional. Trata-se de resultado da queda das taxas de fecundidade e mortalidade e do conseqüente aumento da expectativa de vida (Brasil, 1999; Uchôa et al., 2002).

Estes são alguns dos componentes da transição demográfica $e$ epidemiológica observada em nosso país, que vêm demandando mudanças na atenção à saúde da população, tendo como uma das respostas governamentais a Política de Saúde do Idoso (Brasil, 1999).

Podemos considerar que o aumento da expectativa de vida constitui uma das maiores conquistas sociais da modernidade, não sendo privilégio de alguns países ou classes, mas um fenômeno mundial. Entretanto, em muitas sociedades predominam os valores relacionados à competitividade, capacidade para o trabalho e independência, os quais nem sempre podem ser acompanhados pelos idosos, desvalorizando-se sua condição (Uchôa et al., 2002; Veloz et al., 1999; Mercadante, 1996).

De um modo geral, indivíduos idosos possuem doenças coexistentes, alcançando, em média, seis condições crônicas aos 75 anos de idade, entre as mais comuns: hipertensão, diabetes, artroses, afecções respiratórias, acidentes vasculares, insônia, cardiopatias diversas, infecções urinárias, deficiências visuais, entre outras. Este quadro de cronicidade revela-se como incapacitante e causador de dependência e de fragilidades (Brasil, 1999; Ramos, 1999; Mercadante, 1996).

Entre as dificuldades no tratamento de idosos destaca-se a existência deste quadro de múltipla morbidade em que as enfermidades interferem entre si e se agravam em decorrência das condições sócio-econômicas que implicam a dificuldade de acesso a serviços e tecnologias (Trad, 2002; Ramos, 1999).

Sobrepõe-se a esses fatores o desconhecimento dos indivíduos acerca de suas doenças e/ou a falta de esclarecimentos sobre seus direitos e medidas de controle e prevenção (Carvalho et al., 1998; Navarrete \& Perez, 1998).

$\mathrm{O}$ processo de compreensão e aceitação do adoecimento apresenta fases em que o indivíduo identifica-se como: "estou-doente", "sou-doente" e "soupaciente". O "estou-doente" possui um sentindo abrangente da consciência de sentir-se mal, que se confirma no "sou-doente" que, por sua vez, caracteriza-se pela impossibilidade da produção/criação, o que torna o indivíduo "sujeito-da-doença". Em um momento seguinte, experimenta-se a consciência do "sou-paciente" que implica a busca de atendimento e a "entrega" aos cuidados médicos e familiares (Gomes \& Mendonça, 2002; Alves \& Rabelo, 1995; Herzog, 1991).

A doença "fala" por meio dos sinais e sintomas no corpo do indivíduo, $e$ cada pessoa tem uma maneira própria de vivenciar, interpretar e narrar suas enfermidades, num processo intersubjetivo que se dá a partir do diálogo.

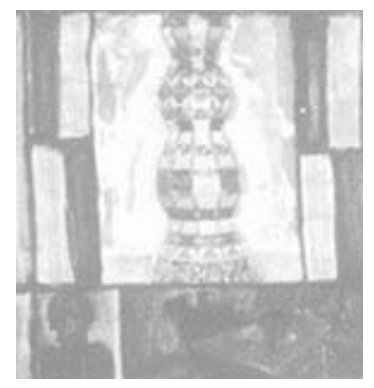


Para a elaboração desses significados individuais e coletivos faz-se necessário evidenciar e compartilhar os códigos em um determinado contexto (Alves $\varepsilon$ Rabelo, 1995; Minayo, 1993).

Do mesmo modo que o adoecer é determinado pela inserção social, o processo de significação também está enraizado na realidade, ou seja, na dependência das condições sócio-culturais conformam-se experiências de enfermidade que permitem aos indivíduos expressá-las. O instituir-se como "sujeito-da-doença" passa pelo saber/discurso médico e pela representação do indivíduo como um corpo, cuidado pelo Estado, que serve para o trabalho/lazer; configurando o caráter histórico e complexo deste processo (Alves \& Rabelo, 1995; Minayo, 1993; Herzog, 1991).

Na sociedade, valoriza-se o tempo e o trabalho, relacionando-se saúde com capacidade laboral, ou seja, estar doente significa não poder exercer atividades (Veloz et al., 1999; Minayo, 1993).

Com a implantação do SUS e a ordenação da rede básica e da estratégia da saúde da família, tem-se maior acesso aos serviços de saúde, bem como a informações. Entende-se que, em locais nos quais este acesso esteja de alguma forma garantido, as pessoas possam integrar sua vivência do adoecimento com explicações deste processo, expressando seu modo de compreendê-lo e aceitá-lo (Gomes E Mendonça, 2002; Trad, 2002).

Num possível diálogo entre profissionais e usuários, deve-se buscar construir um processo de significação que possibilite a narrativa $e$ interpretação numa linguagem compartilhada. Tendo perspectivas distintas, igualmente válidas, pois construídas a partir de experiências cotidianas e de conhecimentos leigos e científicos, pode-se encaminhar um processo de compreensão, por meio da exposição e da apreensão de conflitos e diferenças (Martínez \& Bosi, 2004; Gomes \& Mendonça, 2002; Mercadante, 1996; Alves \& Rabelo, 1995).

Esta pesquisa buscou analisar as percepções de um grupo de idosos acerca do adoecer e envelhecer. Objetivou-se contextualizar suas falas e demonstrar a necessidade e possibilidade de ampliação do diálogo entre profissionais de saúde e usuários.

$\mathrm{O}$ roteiro (script)

Procedeu-se ao trabalho exploratório em duas etapas: uma de estudo quantitativo e outra qualitativo. A construção de um perfil quantitativo sócio-econômico e de morbidade serviu de substrato para a fase qualitativa.

Na primeira etapa, realizada em outubro e novembro de 2002, foram aplicados a pessoas em seus domicílios questionários com informações: sócio-econômicas (gênero, idade, estado civil, escolaridade, ocupação, renda, naturalidade e condições de moradia); de morbidade referida, de acessibilidade a serviços de saúde $e$ a medidas de controle e de prevenção, $e$ confirmação ou negação quanto a esclarecimentos recebidos. As doenças contidas no questionário foram selecionadas de acordo com outros estudos de morbidade, utilizando-se a décima revisão da Classificação Internacional de Doenças (Brasil, 1999; Ramos E Macedo, 1999; Cesar et al., 1996).

Foram sujeitos desta fase cinqüenta idosos escolhidos aleatoriamente 
entre os moradores próximos a duas unidades básicas do Distrito de Saúde Noroeste de Campinas-SP.

$\mathrm{Na}$ segunda etapa, realizada em março e abril de 2003, entre esses indivíduos foram selecionados 11 , segundo amostragem por variedade de tipos de diferentes características: biodemográficas (gênero e faixas etárias), mórbidas e quanto à satisfação com a assistência à saúde (Turato, 2003).

Foram realizadas novas entrevistas, seguindo um roteiro, com itens diretivos relativos às concepções acerca de: envelhecimento e quadro de morbidade, acesso aos serviços de saúde e informações, dificuldades decorrentes da dependência.

Esta metodologia de caráter qualitativo implica limitar o número de entrevistados, mas tendo por contrapartida maior disponibilidade de tempo, maior riqueza de conteúdos com menor generalização, mais aprofundamento e abrangência da compreensão. Um indivíduo pode representar um grupo social cujas idéias resultam de diversos fatores correlacionados e refletem uma realidade que, por sua vez, influi na maneira de pensar e agir daquele grupo. A maneira de pensar e de expor entre os indivíduos é diversa, porém possibilita uma aproximação ao contexto em que foi elaborada. Permite alcançar pontos de vista diferentes, em que o importante é a subjetividade do processo de padecimento (Martínez \& Bosi, 2004; Turato, 2003; Gomes \& Mendonça, 2002; Minayo, 1993).

Após a transcrição das entrevistas, procedeu-se ao trabalho de descrição (o que foi dito), compreensão (aquilo acerca do que se diz) e explicação (porque foi dito) de cada entrevista; seguido da seleção das categorias $e$ subcategorias de análise (Turato, 2003; Alves \& Rabelo, 1995; Minayo, 1993).

Os resultados são apresentados concomitantemente à discussão, iniciando-se pelo perfil sócio-econômico e de morbidade da etapa quantitativa (os sujeitos) e seguidos pelo estudo qualitativo (os sujeitos em cena).

Foram solicitados e assinados, previamente, consentimentos ao trabalho de campo, segundo indicação do Comitê de Ética da instituição.

\section{Os sujeitos}

Da etapa quantitativa participaram 22 homens e 28 mulheres com 71 anos de idade em média. Os homens entrevistados eram, na maioria, aposentados, possuindo uma renda média mensal de 2,5 salários mínimos e as mulheres, donas de casa, com 1,7 salários mínimos de renda. Em relação à escolaridade, a maioria dos idosos freqüentou somente o primário (48\%) $e$ $8 \%$ referiram não saber ler e escrever. Levando-se em conta a moradia, $94 \%$ possuíam casa própria.

A média geral de doenças por pessoa foi de 5,3 enfermidades. Os homens com 4,3 transtornos, sendo os mais prevalentes os visuais (42,8\%); a hipertensão arterial e cardiopatias (38\% cada); e os psicossociais $(28,6 \%$ ). Do total, $57,1 \%$ referiram ser fumantes. A média de enfermidades entre as 28 mulheres entrevistadas foi de 6,1 , sendo mais prevalentes as osteomusculares (82,1\%), a hipertensão arterial (64,3\%); as psicossociais $(60,7 \%)$ e as visuais (50\%). Entre as mulheres, apenas $3,6 \%$ relataram

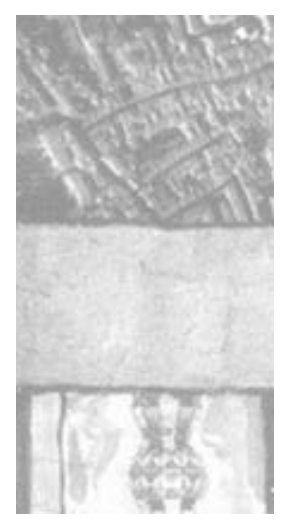


fumar.

A média mais elevada de doenças entre as mulheres sugere um melhor conhecimento da própria saúde, decorrente da procura mais freqüente dos serviços de saúde e maior desenvoltura para a explanação de seus problemas, já que se trata de pesquisa baseada em morbidade referida (Uchôa et al., 2002; Ramos \& Macedo, 1999; Cesar et al., 1996).

Esta conclusão condiz com o achado relativo à diferença entre a referência espontânea e estimulada. Os homens tiveram $55,5 \%$ das doenças relatadas de maneira estimulada e $44,5 \%$ de maneira espontânea, já entre as mulheres ocorreu o inverso: $65 \%$ foram relatadas de maneira espontânea $e$ $35 \%$, estimulada (Cesar et al., 1996).

A utilização de outras medidas para o controle das doenças, além das medicações, é feita por $69,4 \%$ do total de idosos: dieta por $32,3 \%$, exercício físico mais dieta por $29,4 \%$ e somente exercício físico por $26,5 \%$.

Entre os entrevistados, $52 \%$ relataram terem recebido informações sobre suas doenças e $92 \%$ deste total declararam que tais informações foram esclarecedoras. Nota-se que grande porcentagem dos idosos, quase a metade, apontou não ter recebido esclarecimentos, o que representa um dos maiores impasses para a compreensão/aceitação do adoecimento e de um acompanhamento resolutivo.

Os sujeitos em cena

A pesquisa qualitativa contou com os seguintes sujeitos:

Mulheres:

(1) 60 anos, com osteoporose, escoliose, constipação intestinal, depressão, tabagismo.

(2) 62 anos, com hipertensão arterial, artrite, gastrite, sinusite, depressão, varizes.

(3) 65 anos, com hipertensão, cardiopatia, transtorno visual.

(4) 69 anos, com hipertensão arterial, diabetes tipo II, colopatia funcional.

(5) 74 anos, com diabetes tipo II, gastrite, insuficiência venosa.

(6) 75 anos, com diabetes tipo II, hipertensão arterial.

Homens:

(7) 65 anos, com cirrose, hipertensão arterial, transtorno visual.

(8) 65 anos, com hipertensão arterial, osteoartrose, transtorno visual.

(9) 69 anos, com hipertensão arterial, hiperplasia prostática, seqüela de AVE, tabagismo.

(10) 75 anos, com arritmias, enfisema pulmonar, reumatismo, deficiência visual, tabagismo.

(11) 75 anos, com diabetes, hipertensão arterial, gastrite, catarata, bronquite crônica, tabagismo.

O envelhecer

$O$ envelhecer tem sido entendido pela sociedade moderna ocidental como perda ou incapacidade e, mesmo entre os idosos, observa-se esta concepção. 
Tem-se dificuldade em lidar com diferenças e com o fato de que se é portador de alguma necessidade "especial", em algum momento da vida $e$, principalmente, quando se envelhece (Uchôa et al., 2002; Veloz et al., 1999; Mercadante, 1996).

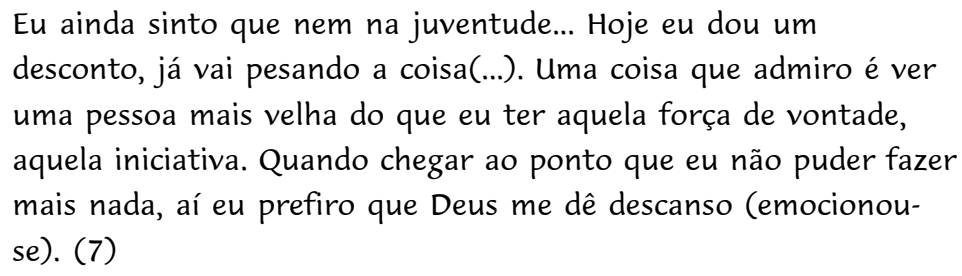

Analisando a idade dos sujeitos em cena, observa-se uma tendência de envelhecimento biológico mais acentuado, com um quadro de múltiplas enfermidades na faixa dos sessenta anos.

Mesmo assim, há importante variabilidade de situações, principalmente quanto aos aspectos psico-sócio-culturais que implicam diferentes modos de vida e de aceitação das perdas ou vantagens do envelhecimento. Alguns têm concepções mais negativas, outros, principalmente as mulheres, mais otimistas (Uchôa et al., 2002; Veloz et al., 1999).

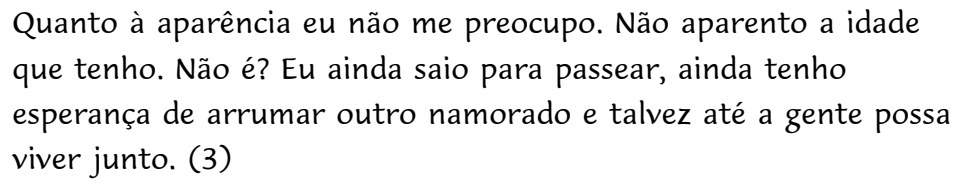

Valoriza-se a manutenção de papéis sociais e a estética, mas o quadro de adoecimento pode acelerar o processo de dependência e a perda da autonomia (Veloz et al., 1999; Mercadante, 1996). "Eu estou vendo eu me entortando, eu fico triste... A dor é tão grande que eu não tenho ânimo para nada, não consigo levantar para ir ao portão” (1).

O adoecer envelhecendo

O adoecer tem múltiplas representações. Na população trabalhadora é percebido, principalmente, pela incapacidade para a atividade laboral (Alves E Rabelo, 1995; Minayo, 1993). "Esta dor nas pernas me impede de andar, me dá tontura na rua. (...) Não está dando mais para fazer uma faxina. Será que estou tão incapacitada assim?” (1).

É referido também como um descontrole sobre o próprio corpo, confundindo-se com a heteronomia, num processo de perda que representa inutilidade (Veloz et al., 1999; Mercadante, 1996).

Eu não faço mais nada, nem varrer nem nada. (...) Fala as coisas agora e já esqueço. Não seguro nada na cabeça. (...) Com o enfisema, trabalhar acabou. Nem fazer cobrança. (...) Eu operei esta vista, mas não enxergo quase nada. (10)

O envelhecer, como apontado, é entendido como incapacidade e 
dependência, necessitando-se de cuidados especiais.

Quando eu fiquei ruim, eu fiquei desgovernado. (...) Só sabia que estava vivo. Meu corpo ficou desligado de tudo. Eu fazia todas as necessidades na cama, cheguei a usar fraldas e nem sabia. Minha mulher, uma vizinha super bacana, e meu filho cuidavam de mim.

A depressão e alterações do estado de ânimo (de alta prevalência entre idosos, mas pouco diagnosticadas) foram referidas enquanto transtornos altamente incapacitantes (Brasil, 1999; Mercadante, 1996).

\footnotetext{
A depressão me dá muita insegurança. Não consigo manter contato com muita gente. Tenho insegurança de sair, ir num banco, preencher um cheque (...) eu tenho receio, ainda sinto que sou menor. Acho que vou falar coisa errada, acho que aquela pessoa sabe mais do que eu. (2)
}

A cronicidade é uma característica fundamental do adoecer no envelhecimento. "A diabetes não me preocupa. Já acostumei com a doença, convivo com ela há mais de 10 anos" (11).

As enfermidades apresentam-se, em geral, de forma insidiosa $e$ assintomática, e na dependência do acesso aos cuidados de saúde, podem ser diagnosticadas somente após complicações, ou consideradas distúrbios próprios da idade e não passíveis de tratamento (Carvalho, 1998). "Não, doença eu não tenho. (...) Eu descobri que tinha pressão depois que eu tive uma espécie de derrame. (...) Agora, está controlada, não me atrapalha. Eu saio normalmente. Tomo os remédios (9).

As repercussões do adoecer acentuam-se em decorrência das condições sócio-econômicas adversas, como é o caso dos entrevistados. "Eu não sei porque eu perdi minha vista muito cedo, foi com cinqüenta e cinco anos. Eu preciso dessa vista para ajudar meu pai. Ele é doente” (8).

A avaliação da gravidade e da relevância do problema parece determinada pela possibilidade de enfrentamento. "Se cai e morre ainda é bom!? O pior é se ficar penando na cama dando trabalho para os outros." (11)

Em conseqüencia de se conceber o envelhecer e o adoecer como incapacidade, há no idoso um processo, ainda mais profundo do que na população geral, de subjugação à doença, de "ser-paciente" e entregar-se nas mãos dos médicos e familiares (Gomes \& Mendonça, 2002; Alves \& Rabelo, 1995).

Mesmo depois que eu operei a catarata a vista melhorou, mas eu fiquei com medo. A cabeça é que não está boa. Tenho medo de sair, medo de atravessar, de ir à cidade. Preciso de um companheiro. Eu atravesso a rua assim e um carro me pega. (11)

Pode-se, por meio destas percepções, refletir e compartilhar a aceitação ou negação do envelhecer e do adoecer com cada indivíduo (Gomes \& 
Mendonça, 2002; Alves \& Rabelo, 1995; Herzog, 1991). "Meu medo é de uma hora ficar ruim de repente com a pressão e morrer (risada)" (3).

\section{Representações de quadros mórbidos específicos}

A caracterização das doenças por parte dos idosos ocorre das mais diversas formas e constata-se que se baseia, principalmente, no reconhecimento de sintomas e sinais, ou seja, no reconhecimento da enfermidade no próprio corpo (Navarrete, 1998; Minayo, 1993).

Expressaram sintomas clássicos de algumas doenças, como:

- a hiperfagia e polidipsia no diabetes: "Antes de virá diabética eu comia um prato cheio de comida assim, ó (gesticula com a mão um formato de monte) e bebia tanta água que num sei como a barriga não estourava!” (4).

- os sinais de um edema: "Para ver se estou inchada eu aperto aqui na perna e vejo se forma aquele buraquinho. (...) Na palestra do postinho a gente foi orientada como deitar para desinchar os pés" (5).

- ou de uma disfunção urinária: "Dava uma vontade de ir ao banheiro, eu ia depressa quando via saía só aquela gotinha, doía muito” (1).

As pessoas indicaram apropriar-se de conhecimentos relacionados aos fatores causais e fisiopatologia de seus transtornos.

Começou com uma sinusite, depois bronquite, depois peguei tuberculose. Tratei e fiquei bom. Agora, fiquei ruim de novo. Fiquei internado 12 dias. Aí o médico falou: ah, isso não tem mais jeito, é enfisema pulmonar. Vai tomar remédio e ir mantendo. Esta doença não tem cura. (...) Essa coisa é culpa do cigarro. (10)

Tenho problema nas juntas. Não sei se foi devido o sobe, desce, descarrega, carrega, durante vinte e seis anos, soltando carga para ajudantes. Forcei muito quando era mais moço. (8)

Reconheceram algumas complicações (Navarrete, 1998). "Eu sei que se a gente não tomar remédio pode entrar em coma. (...) Eu sentia desânimo, emagreci muito! Até as colegas falavam: que regime a senhora está fazendo? Que regime o quê!? Era a diabetes!"(5).

No caso de transtornos psicossociais, ficou demonstrada a complexidade do quadro, lançando-se mão de explicações de ordem religiosa.

A minha depressão é em parte emocional. (...) Olho no espelho e vejo que não tem nada, mas eu sinto que na minha cabeça dá um branco. Aí eu não sei falar, não sei conversar... É muito doloroso. (...) Se recebo uma notícia que nem a de sábado que meu irmão deu derrame, eu já... Mas aí a gente tem um Poderoso. Eu tenho muita fé em Deus. Ele me dá força.(...) O médico é nosso conselheiro, nosso amigo e enviado por Deus. (2)

Observou-se o conhecimento das ações preventivas e de controle indicadas em cada caso. "A pressão não me atrapalha, porque tomo remédio e 
controlo há muitos anos. Todos os dias eu faço caminhada, que não fazia antes e muita coisa que eu sei que faz mal eu não como..." (3).

Tais orientações foram apreendidas em diferentes espaços, principalmente com a própria experiência do adoecer e cuidar-se. "Eles explicaram que a diabetes era um problema no pâncreas, que o açúcar passava o nível no sangue daquela taxa certa. Se abaixar muito também dá problema" (6).

A maior parte dos idosos entrevistados demonstrou esta apropriação e a possibilidade de expressão de seu quadro, trazendo inclusive explicações mais amplas do processo de adoecimento, no sentido da integralidade, enquanto desafio para o cuidado em saúde.

\begin{abstract}
A pressão atrapalha muito! Mudou a minha vida. Uma hora ela está normal e daqui a pouco está alta. (...) Acho que tem a ver com a vida. Você não tem aumento, toda a vez que vai no mercado o preço é diferente. Quem agüenta? É o dia a dia que faz a pressão subir! Por exemplo, este negócio da matança aí. Eu nem gosto de assistir TV (...) Não dá mais para sair no portão.
\end{abstract}

Eu trabalhava numa firma, construía casa, prédios. Eu pegava cimento o dia inteiro. (...) Chegou um caminhão com uns 600 sacos de cimento e eu carregando direto... Assim que abaixei vi uns vaga-lumes na minha frente. (...). Fui no posto, minha pressão tava 22. (11).

A utilização de figuras de expressão, como as metáforas, é muito freqüente na linguagem popular, tanto para explicar suas doenças como a cronicidade ou o processo de envelhecimento. Elas permitem, de modo singular, dar forma ao sofrimento individual (Alves \& Rabelo, 1995; Minayo, 1993). " $A$ única coisa que sei é que é uma cárie nos ossos" (osteoporose) (1). "O médico falou que o fígado tava secando, tava murchando. Eu falei: seco não pode porque está muito molhado! (risada) (...) Eu estava no bico do corvo" (7).

É importante retomar que ao descrever seu quadro o indivíduo constrói significados que possibilitam processar sua aceitação.

\title{
Dificuldades em cena
}

O distanciamento entre os profissionais e os usuários, entre os que detêm os conhecimentos e termos técnicos e as demais pessoas, foi explicitado em muitas situações. Queixaram-se da falta de explicações e do uso de uma linguagem inacessível, que explica a procura de outras fontes de informação.

Quem explicou para mim o que era a diabetes foi um farmacêutico. Eu acho que confio mais nele do que no médico (...) Eu ficava direto no bebedouro e depois no banheiro. $\mathrm{O}$ farmacêutico disse: Você vai fazer um exame... E deu açúcar no sangue. Ele explicou que era diabetes, um problema que vem de 
Trata-se de um distanciamento que se reproduz durante a investigação, sendo que em quase todas as entrevistas ao se perguntar se a pessoa sabia o que "causava" a sua doença, a resposta obtida foi "não, eu não sei". Foi observado o medo de falar "errado", de não corresponder àquilo que seria esperado, mas que pode ser suplantado quando se estabelece uma relação de confiança e respeito ao conhecimento de cada um. "No grupo eles explicam, mas a gente não consegue entender direito. Falam do coração que pode ficar ruim com a pressão, e pode dar um monte de problemas" (4).

Confirmou-se a carência de explicações durante as consultas médicas individuais, que acabam mantendo a situação de "sujeitos-da-doença" (Alves E Rabelo, 1995; Herzog, 1991). "O médico não me explicou o que era este enfisema. Só depois que eu tive tuberculose é que me disseram que eu teria que tomar remédio a vida toda" (10).

Ficou também demonstrado o limite da consulta médica no que tange às informações sobre os problemas diagnosticados. "Não, o médico não me explicou sobre a pressão (...) Falou para tomar remédio e comer com pouco sal. Ele perguntou se eu fumava. (...) Não falou para eu parar" (9).

Foram exemplificadas situações nas quais houve a intenção da explicação pelo profissional, mesmo com a dificuldade de se utilizar conceitos, e uso de uma linguagem adequada.

A médica me explicou e eu entendi. O problema da pressão acho que o negócio é no coração. Uma veia mestra, não sei como chama. Ela disse que quando ela bobeia para jogar o sangue para as outras veias, ela não agüenta então sobe a pressão. ...Não tem cura, não sara, só tem tratamento e se combate com o remédio e controle. (3)

Outra dificuldade referida pelos entrevistados foi relativa à mudança de hábitos (Carvalho, 1998; Navarrete, 1998). "Estou fumando menos, mas é difícil parar. Já tentei, mas continuo com a mesma falta de ar. Tenho que correr para a inalação" (10). "Ah... o médico falou que tem que comer cinco vezes... Meu estômago não aceita isso não, e não dá pra comer sem fome não" (6). "A diabetes incomoda porque tem muita coisa que a gente gosta não pode comer: feijoada, doce, uma carne gorda (...) Os médicos dizem para comer folhas. A gente não é mandruvá!” (11).

Foi patente a dificuldade de se entender e explicar problemas crônicos multifatoriais como a diabetes e a hipertensão, mas que poderiam ser clareados partindo da escuta e da construção de narrativas compartilhadas (Carvalho et al., 1998; Alves \& Rabelo, 1995).

$\mathrm{O}$ diabetes, eu creio, vem de família. Meu pai morreu por causa disso e cego. Lá em Minas não tinha um médico. Ninguém usava fazer exame de sangue..(...)Ele bebia água o dia inteiro na roça $e$ quando tinha um machucadinho demorava para sarar. (11)

Demonstrou-se a insuficiência da medicina em explicar e cuidar de

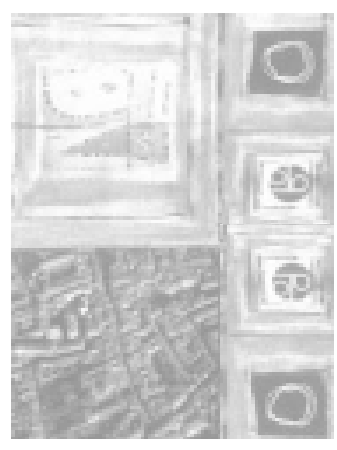


transtornos psicossociais e degenerativos, o que implica a somatização para a obtenção de cuidados.

Eu ia ao médico com o eletro na mão rezando para que desse alguma coisa e parte psicológica não dá no eletro e eu chorava muito. (...) Um dia o médico perguntou para mim porque eu estava chorando, olhou no meu rosto e disse: Dona ... , papel não fala, não tem sentimento. Eu baixei a cabeça e fiquei quieta. Aí eu comecei a entender. (2)

Outra dificuldade citada foi relativa à prescrição das medicações que não se ajusta às características da clientela (em parte, analfabeta ou com distúrbio visual) e apresenta mudanças freqüentes dos padrões e denominações dos produtos, somando-se a necessidade de múltiplos medicamentos, as deficiências na sua aquisição pela rede pública $e$ a impossibilidade de adquirilos no comércio.

Queixaram-se da demora para o agendamento de consultas e do tempo de espera para o atendimento. "Aqui no centro não consegui marcar consulta, sete horas na terça já estou lá e já tem muita gente na frente. Fica para outra semana... aí o médico não vem" (1).

Foram manifestadas insatisfações com o SUS e a visão de que os convênios resolveriam.

Eu fico com medo de ficar numa hora ou outra mais grave e eu não tenho convênio. Primeiro eu tinha, mas não agüentei pagar... Correr para o pronto-socorro é uma lástima! Outro dia fiquei ruim, fui no posto, fiz consulta e tirei sangue para exame, mas no posto demora, não é como no convênio que é rapidinho. (3)

\section{Novos cenários}

Observou-se que a experiência dos idosos, somada ao acesso a informações possibilitou a construção de conhecimentos. Destacaram-se, enquanto fontes de informação os grupos educativos, farmacêuticos e pessoas próximas. "O médico me disse que estava com osteoporose. Pois o RX no visor e falou: é aonde a senhora vê o osso mais fino, com buraco. (...) Também aprendi na palestra do postinho que tem uma vez por semana" (1).

Ficou demonstrando que tem havido uma ampliação significativa do acesso aos serviços de saúde, principalmente a unidades básicas e de saúde da família (Trad, 2002; Brasil, 1999).

Eu estava assim cego. Eu não reconhecia nem minha mulher. Foi a catarata, Ai eu operei e graças a Deus eu enxergo uma formiga numa distância de $10 \mathrm{~km}$. (...) Eu trato a diabetes no posto. É muito bom, para mim. Tomo comprimido para a pressão $e$ insulina. Eu mesmo me aplico. No princípio eu ia no posto. Aí, falei para a (auxiliar de enfermagem) para me ensinar a aplicar aquele negócio. Ah, ensino... Na primeira vez fiquei com medo... 
Nossa Senhora Aparecida! Enfiei a agulha assim... Faz cinco anos que eu mesmo me aplico. (11)

Foram descritas situações em que ocorreu o acolhimento às necessidades dos idosos, o que indica a mudança do modelo assistencial. "Quando eu acho que eu vou sentir alguma coisa, quando a pressão sobe um pouco, eu vou ao Centro de Saúde. Aí a (auxiliar de enfermagem) fala: subiu um pouco a pressão. (...) Tomo o remédio, como com pouco sal" (9).

Os entrevistados citaram inúmeras informações recebidas, principalmente nos grupos educativos. "Depois que tive diabetes a médica disse que precisa caminhar (...) caminho cedo e à tarde. O pessoal do grupo pega no pé também. Explicam para não comer muito pão, frituras, massa” (5).

Comumente, acredita-se que os idosos, principalmente de categorias sociais desfavorecidas, não são capazes de explicar seus adoecimentos. No entanto, as entrevistas e, principalmente, o retorno aos domicílios, com a criação de um certo laço de confiança e oportunidade do diálogo, demonstraram o equívoco desta consideração.

Olha, minha filha pode ajudar a explicar. (...) Eu tenho cirrose, mas meu problema maior é que tenho só um rim. (...) Sinto muita dor, tenho muita canseira. Eu era atleta. Na época, eu não sentia nada. (...) eu sou muito teimoso, comecei a tomar umas a mais e aí estragou tudo. (7)

A depressão e outras alterações do estado de ânimo, que não haviam sido referidas no momento da pesquisa quantitativa foram manifestadas, mostrando-se fatores determinantes do adoecimento.

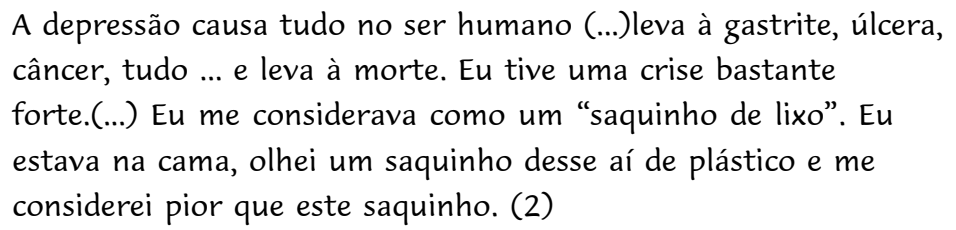

Como aspecto positivo relacionado à satisfação com o atendimento nas UBS foi referido o acesso a práticas alternativas e à equipe multiprofissional. "Terça e quinta tem tai chi chuan. Vou entrar no grupo Reviver para fazer exercícios com eles e ainda acupuntura com o doutor ..."(1). "Tive um derrame, a mão ficou virada, ficou um mês assim. Ai, depois de fisioterapia eu melhorei. Depois de dois meses, voltei a trabalhar. Já tava bom” (9).

Foram citadas situações, principalmente relacionadas às atividades em grupos terapêuticos nestes serviços, que se portaram empreendedoras de relacionamentos. "No grupo a gente conhece pessoas, fala mais, conversa mais, faz amizades. (...) pode trocar idéias e às vezes fazer algum trabalho. Gosto de sair, a gente vai andar e conversa. A palestra da médica também é boa" (5). 
Como demonstrado nas falas, constituiu-se uma rede de apoio social na qual a família e a comunidade têm papel fundamental (Uchôa et al., 2002; Trad, 2002; Mercadante, 1996).

\author{
Os familiares não sabem como ajudar. É muito difícil na \\ depressão, principalmente para o marido. (...) Ele falava que era \\ frescura, preguiça. A família precisa também entender. (...) Agora \\ é diferente. Quando meu marido vê que eu estou deprimida eu \\ vou para o sofá e ele vai para o fogão. (...) a Maria, minha amiga, \\ também me ajuda a sair da cama, me dá um ombro amigo. (2)
}

Registrou-se a articulação entre instituições públicas, religiosas e culturais. "Eu estou ajudando a fazer uma campanha na Igreja para ajudar as pessoas a parar de beber (1)".

\footnotetext{
Hoje eu gosto muito do que faço. Ajudo o próximo. Aqui nesse meu bazarzinho vem gente só para conversar. Ontem Deus mandou um senhor aqui, só para aumentar minha auto-estima. (...) Ele olhou para mim e falou: A senhora é uma mulher de Deus. É uma senhora muito bacana. (2)
}

A relação profissional/usuário foi valorizada pelos idosos e seus familiares. "Só de conversar com vocês passou a dor no meu pé, foi um prazer"(1). "Eu trabalho em casa. Eu ajudo a mulher. Somos só nós dois e o rapaz. Ele trabalha, ela faz o almoço, eu arrumo a cozinha" (11). "Aqui morava meu irmão que faleceu. Ele morreu e eu fiquei sozinho, sou solteiro. Minha irmã mora vizinha. Ela faz a comida para mim" (9).

Um dos desafios para os serviços na atenção aos idosos é o de conhecer $e$ otimizar estes recursos, possibilitando a ampliação da resiliência por meio de uma rede constituída socialmente.

\title{
Cortinas abertas
}

$O$ envelhecer $e$ o adoecer apresentam uma dimensão contingencial $e$ situacional decorrente da pluralidade de experiências, narrativas e interpretações. Como fenômenos sócio-culturais e biológicos, cada indivíduo reage com base em suas referências (Uchôa et al., 2002).

A melhor compreensão dos profissionais em relação à maneira de o idoso expressar-se e entender seu processo de adoecer e envelhecer permite um relacionamento mais eficiente, contribuindo tanto para o diagnóstico como para o acompanhamento.

Trata-se de uma preocupação que não se limita à adesão ao tratamento, mas à possibilidade de ampliar o diálogo e negociação dentro de uma ética de respeito às diferenças que, expressas, poderão ser discutidas em busca de autonomia $e$ independência no cuidado da saúde, com responsabilização compartilhada (Martínez \& Bosi, 2004; Gomes \& Mendonça, 2002).

Esta investigação procurou aproximar-se de um método a ser apropriado pela clínica, no qual a escuta e o diálogo representam tecnologias a serem desenvolvidas pelos profissionais. 
Não se tem um acesso direto à experiência dos outros. Durante a narrativa, o indivíduo revela vivências biográficas, articulando o passado, o presente e o futuro, ou seja, no ato de narrar/escutar propiciam-se novas reflexões, conduzindo a remodelações de perspectivas anteriores (Gomes $\mathcal{E}$ Mendonça, 2002).

Neste enfoque prevalece a lógica na qual o adoecimento procede do sujeito, devendo ser valorizado e codificado por este, sendo a cura uma atividade reguladora, visão que se contrapõe à concepção biomédica que descreve a doença a priori do sujeito, que deveria ser combatida. Não basta também substituir o modelo de comunicação paternalista (do sujeito de doença que se entrega às decisões médicas) para um modelo informativo (o profissional informa e presta serviço e a responsabilidade é do paciente), mas uma intenção comunicativa (Gomes \& Mendonça, 2002; Alves E Rabelo, 1995; Herzog, 1991).

Desta forma, não se pretende que os resultados desta análise se reproduzam "em si", reificando-se os conteúdos narrados, mas pleiteia-se a compreensão da existência de aspectos mediadores do processo de enfermidade, entre os quais: o próprio quadro de morbidade, o acesso qualitativo aos serviços e informações, o vínculo entre usuários $e$ profissionais, o apoio familiar e comunitário, as condições financeiras da família, as diferenças de gênero e a própria história de vida e de inserção social que implicam a interpretação e aceitação do envelhecer (Gomes \& Mendonça, 2002).

Dar significação a essas mediações pode qualificar o cuidado em saúde, aliviando o sofrimento do adoecer e desconstruindo a visão alarmista $e$ preconceituosa do envelhecimento. Existem perdas, mas não são específicas ou privilégio da velhice. Há uma dimensão pragmática da significação e da narrativa como integrante do cuidado, da ação de experimentar cotidianamente o ser-doente ou ser-sujeito (Uchôa et al., 2002; Herzog, 1991).

Outra questão metodológica que precisa ser identificada na relação entre a clínica e a investigação qualitativa é a que supervaloriza a subjetividade do adoecimento, considerando a percepção como "verdadeira", criando-se uma "ilusão de transparência", da mesma forma que a concepção positivista da verdade absoluta do conhecimento técnico-científico subjuga a narrativa/ significação do indivíduo. Ambos, saber popular e técnico, precisam ser decodificados, reconstruídos na ação clínica (Martínez \& Bosi, 2004; Gomes E Mendonça, 2002).

É interessante destacar a necessidade de uma linguagem adequada. A comunicação com os idosos pode ser facilitada, por exemplo, pelo uso de figuras de linguagem (metáforas), as quais reproduzem uma imagem mental que permite o entendimento compartilhado, pois comovem, persuadem e ampliam a significação (Alves \& Rabelo, 1995).

Entre as explicações para os resultados desta investigação, no que tange à riqueza de representações narradas pelos idosos sobre seu padecimento, bem como às formas de controle e prevenção, destaca-se o acesso a serviços de saúde pública (unidades básicas e de saúde da família).

Foram citadas situações de acolhimento, o que indica o encaminhamento 
de uma mudança do modelo assistencial, mas também queixas relativas à falta de responsabilização e vínculo com os profissionais e equipe de saúde. Algumas falas apontam alternativas para a melhoria dos equipamentos sociais, que dependeria de medidas desempenhadas pelo poder público, ou por entidade não governamental.

Na compreensão do adoecer com cronicidade é importante também aquilatar perdas e ganhos do envelhecimento. Alteram-se os papéis sociais, diminuem o ritmo e a capacidade para o trabalho, surgem rugas e mudanças corporais estéticas, mas surgem também outros atributos relacionados à experiência e sabedoria (Uchôa et al., 2002; Veloz et al., 1999; Mercadante, 1996).

Pode-se minorar a morbidade múltipla e suas complicações por meio do diagnóstico precoce ou de medidas de prevenção secundária e terciária, mas, principalmente com o diálogo, pode-se cuidar do sofrimento, possibilitando um envelhecimento mais saudável.

Espera-se contribuir para a mudança de um modelo de cuidado que tenha por perspectiva o sujeito em sua singularidade, o que pode nos ensinar a lidar com nossas próprias fraquezas e dificuldades no adoecer, amadurecer $e$ envelhecer.

\section{Referências}

ALVES, P. C.; RABELO, M. C. Significação e metáforas: aspectos situacionais no discurso da enfermidade. In: PITTA, A. M. R. (Org.) Saúde \& comunicação: visibilidades e silêncio. São Paulo: Hucitec/Abrasco, 1995. p.217-35.

BRASIL. Ministério da Saúde. Política de saúde do idoso. Portaria n.1.395/GM, de 10 de dezembvro de 1999. Brasília, 1999. Disponível em: <http://www.funasa.br>. Acesso em: 20 mai. 2002.

CARVALHO, F.; TELAROLLI JUNIOR, R.; SILVA, J.C.M. Uma investigação antropológica na terceira idade: concepções sobre a hipertensão arterial. Cad. Saúde Pública, v.14, n.3, p.617-21, 1998.

CESAR, C. L.G.; FIGUEIREDO, G. M.; WESTPHAL, M. F.; CARDOSO, M. R. A.; COSTA, M. Z. A.; GATTÀS, V. L. Morbidade referida e utilização de serviços de saúde em localidades urbanas brasileiras: metodologia. Rev. Saúde Pública, v.30, n.2, p.153-61, 1996.

GOMES, R.; MENDONÇA, E. A. A representação e a experiência da doença: princípios para a pesquisa qualitativa em saúde. In: MINAYO, M.C.S.; DESLANDES, S.F. (Org.) Caminhos do pensamento: epistemologia e método. Rio de Janeiro: Fiocruz, 2002. p.109-32.

HERZOG, R. A percepção de si como sujeito-da-doença. Physis: Rev. Saúde Coletiva, v.1, n.2, p.14355, 1991.

MARTÍNEZ, F. J.; BOSI, M. L. M. Introdução: notas para um debate. In: BOSI, M. L. M.; MERCADO, F. J. (Org.) Pesquisa qualitativa de serviços de saúde. Petrópolis: Vozes, 2004. p.23-71.

MERCADANTE, E. Aspectos antropológicos do envelhecimento. In: PAPALÉO, M. N. (Org.)

Gerontologia. São Paulo: Atheneu, 1996. p.73-6.

MINAYO, M. C. O desafio do conhecimento: pesquisa qualitativa em saúde. 2.ed. São Paulo/Rio de Janeiro: Hucitec/Abrasco, 1993.

NAVARRETE, M. F. J.; PÉREZ, L. R. Perfil educativo en los pacientes crónicos. Rev. Med. Costa Rica y Centro América, v. 543, p.89-93, 1998.

RAMOS, L.R.; MACEDO FILHO, J. M. C. Epidemiologia do envelhecimento no Nordeste do Brasil: 
GARCIA, M. A. A. ET AL.

resultados de inquérito domiciliar. Rev. Saúde Pública, v.33, n.5, p.445-53, 1999.

TRAD, L. A. B. Estudo etnográfico da satisfação do usuário do Programa de Saúde da Família (PSF) na Bahia. Ciênc. Saúde Colet., v.7, n.3, p.581-9, 2002.

TURATO, E. R. Tratado da metodologia da pesquisa clínico-qualitativa. Petrópolis: Vozes, 2003.

UCHÔA, E.; FIRMO, J. O. A.; LIMA-COSTA, M. F. F. Envelhecimento e saúde: experiência e construção cultural. In: MINAYO, M. C.; COIMBRA JR., C.E.A. (Org.) Antropologia, saúde e envelhecimento. Rio de Janeiro: Fiocruz, 2002. p.25-35.

VELOZ, M. C. T.; NASCIMENTO-SCHULZE, C. M.; CAMARGO, B. V. Representações sociais do envelhecimento. Psicol. Reflex. Crit., v.12, p.479-501, 1999.

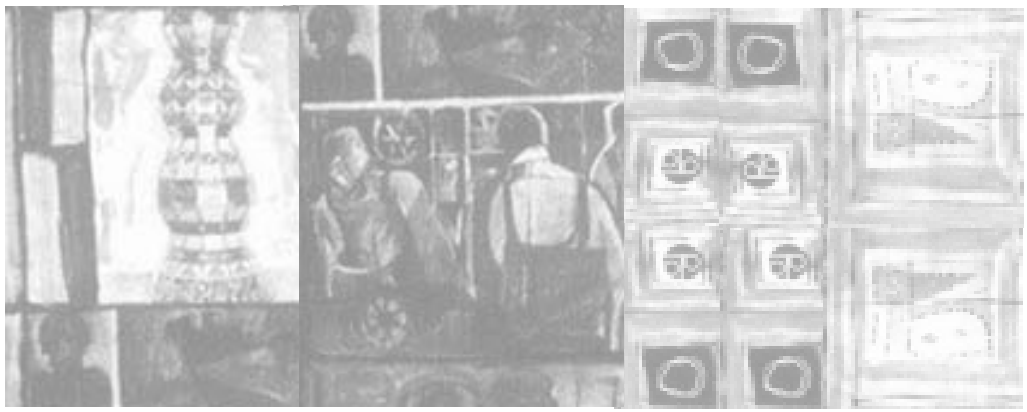

GARCIA, M. A. A. et al. Ancianos en escena: los discursos de enfermarse. Interface Comunic., Saúde, Educ., v.9, n.18, p.537-52, set/dez 2005.

Con la preocupación de una mejor calidad y resolución en la atención a la salud de las personas mayores y al constatar un cuadro de múltiple morbididad de difícil control y prevención, se buscó conocer estos problemas, bajo la perspectiva de los propios sujetos: su entendimiento acerca del proceso de adolecer y de los cuidados necesarios. A través del estudio cualitativo se verificó que la percepción de enfermarse, entre las personas mayores, es principalmente basada en el estilo de vida y en la referencia de la capacidad para el trabajo. Se demostró el acceso a los servicios de salud y el conocimiento técnico de las enfermedades, descritos por la presencia de señales y síntomas y factores causales y asociados. Sin embargo, como experiencias personales que incorporan vivencias de cuidad, las narrativas necesitan ser compartidas, analizando sus mediaciones, lo que les permitiría a los profesionales de salud una aproximación al contexto del adolecer y del envejecer, $y$ al proceso de aceptación y, así, a un cuidado integral y fundado en la búsqueda de autonomía.

PALABRAS CLAVE: salud de la persona mayor. percepción. enfermarse. envejecimiento.

Recebido para publicação em: 16/12/04. Aprovado para publicação em: 18/08/05. 